\title{
Trends in tagging of marine mammals: a review of marine mammal biologging studies
}

\author{
T Mclntyre \\ Mammal Research Institute, Department of Zoology and Entomology, University of Pretoria, Hatfield, South Africa \\ e-mail: tmcintyre@zoology.up.ac.za
}

\begin{abstract}
The number of scientific papers resulting from biologging instruments deployed on marine mammals is increasing as improved technologies result in smaller devices and improved sensor-, storage- and transmission capabilities. I undertook a comprehensive review of papers resulting from biologging deployments on free-ranging marine mammals between 1965 and $2013(n=620)$ to summarise where (e.g. on which species, as well as in which geographic areas) deployment efforts were focused, the impacts of the resulting papers, and where there are shortcomings in the literature. Species-, sex- and age-class biases were evident in terms of animals instrumented. Also, large proportions of the papers resulted from deployments on a small number of species (particularly among the pinnipeds) and were more often on adult females than other demographic classes. The mean impact of papers (as assessed using journal impact factors and numbers of citations) was consistent over time, and was influenced by the number of species studied, sample sizes and instrument capabilities. I found a paucity of papers addressing device influences on animals, as well as studies with explicit conservation and/or management implications. This review aims to increase awareness of marine mammal biologging data already collected, stimulate appropriate further studies, and encourage the reuse of existing data.
\end{abstract}

Keywords: animal-borne devices, cetaceans, pinnipeds, satellite tracking, time-depth recorders

\section{Introduction}

Biologging generally refers to the science associated with the use of animal-borne devices to gather information on the behaviour, movements and physiology of animals, and/ or on the environments they use. Whereas the term itself was apparently coined around the International Symposium on Bio-Logging Science, held at the National Institute of Polar Research, Tokyo, in 2003 (Naito 2010), the science of biologging is somewhat older and is recognised to have started as early as the 1940s, when depth gauges were used on whales and seals (Scholander 1940). After Scholander, the earliest biologging devices used on marine animals are generally recognised to be the maximum-depth recorder (DeVries and Wohlschlag 1964) and time-depth recorders (Kooyman 1965), all of which were deployed on Weddell seals Leptonychotes weddellii (Evans et al. 2013).

Technological advances are increasingly allowing for the miniaturisation of devices, as well as the incorporation of more sophisticated sensors into animal-borne instruments. For example, the use of fast-loc GPS technology (e.g. Dragon et al. 2012a), accelerometers (Naito et al. 2010) and camera systems (e.g. Naito et al. 2013) is allowing more detailed and fine-scale assessments of marine animal movements and behaviour. Furthermore, the addition of various sensors to biologging instruments is contributing increasingly to our understanding of ocean physical properties (Fedak 2013) and how marine mammals adjust their behaviour in relation to them (e.g. Mclntyre et al. 2011a; Jaud et al. 2012; Bestley et al. 2013). Although the technological advances are clear, it is of interest to know how these technologies are applied in scientific studies and what specific questions are being addressed.

Biologging devices are currently used in scientific studies of numerous taxa, including terrestrial mammals (e.g. Hetem et al. 2012; McFarland et al. 2013), reptiles (e.g. Dubois et al. 2009; Watanabe et al. 2013), birds (e.g. Dean et al. 2013; Phipps et al. 2013), fish (e.g. Bonfil et al. 2005; Yasuda et al. 2013) and even invertebrates (e.g. Stewart et al. 2012; Watts et al. 2012). Given the obvious difficulties in observing animals at sea directly, the use of biologging technologies is ideally suited for studies involving marine animals, particularly semi-aquatic species that haul out on land, thereby providing opportunities for the deployment of instruments. Marine biologists (and marine mammalogists in particular) are increasingly making use of biologging technology. This is exemplified by the study species reported in the titles and abstracts of presentations $(n=$ 
165) at the Fourth International Science Symposium on Bio-logging (held 14-18 March 2011 in Hobart, Australia), where $93 \%$ were marine species and $53 \%$ marine mammals (Program and Abstracts document; available at http://www. cmar.csiro.au/biologging4/documents/AbstractsandProgram_ final.pdf).

Here, I review the scientific papers that have resulted from the deployment of animal-borne devices on free-ranging marine mammals between 1965 and 2013. I aim broadly to summarise where (e.g. which species and geographical area) the deployment efforts were focused, the impacts of these papers, and where there are gaps and shortcomings to be addressed in the future. I aim specifically to answer the following questions:

- What are the trends in publication numbers resulting from biologging deployments on marine mammals?

- Which groups and species have carried biologging devices most frequently, and for which species are there few or no publications from biologging deployments?

- In which geographic areas have biologging deployments on marine mammals been focused?

- What are the trends in numbers of devices deployed, types of devices deployed and types of data reported on from biologging deployments on marine mammals?

- What proportion of marine mammal biologging studies is of an applied nature with direct conservation and/or management implications?

- What are the research fields within which the resulting data have been used and where are the papers resulting from biologging deployments on marine mammals published?

- What are the trends in terms of the impact of these papers (as measured by journal impact factors and numbers of citations), and which factors (e.g. numbers of authors, numbers of devices deployed, instrument types, etc.) influence the overall impact of papers?

\section{Material and methods}

For this review I focused on scientific papers in peerreviewed journals that used data obtained through the use of biologging techniques on free-ranging marine mammals. Analyses were restricted to papers published up to and including 2013, and excluded book chapters, conference abstracts and so-called 'grey' literature (e.g. government reports, etc.). I attempted to include as many papers as I could find in the review and hence selected literature search terms that ensured a broad scope. I used primarily the ISI Web of Science and Scopus databases to search for relevant papers using a variety of search terms that included (but were not restricted to): 'biologging', 'timedepth recorder(s)', 'satellite tag(s)', 'Argos', 'GPS', 'geolocation', 'accelerometer(s)', 'telemetry', 'migration', and 'dive behaviour'. Relevant papers cited in papers identified were also searched for individually and included. I further undertook author searches in Scopus for authors known to have published relevant articles, and scanned through all their recorded papers for more papers to include. Whereas it is possible that some relevant literature remained undetected, it is probable that the number of omissions was small and that literature reviewed represented the bulk of the scientific papers published in the field of biologging deployments on marine mammals.

For each paper, I recorded the following parameters (when reported):

1. Year of publication.

2. Species, Family, Suborder and Order of marine mammals that carried instruments. Here, I followed the naming convention for species as published by the Society for Marine Mammalogy (Committee on Taxonomy 2013). I retained Pinnipedia in the analyses as a clade that included the families Odobenidae, Otariidae and Phocidae. Also, I retained Cetacea at the Order level, and recognised Mysticeti and Odentoceti at Suborder level.

3. The location where deployments were made. Where coordinates were not reported, but place names provided, I estimated coordinates of the tagging locations using Google Earth images (https://earth.google.com/; accessed during 2013).

4. The conservation status of all species that carried instruments (as defined by the IUCN Red List of Threatened Species ${ }^{\mathrm{TM}}$ website [http://iucnredlist.org, accessed 31 March 2013]). I did not consider the conservation status of local populations, but only the status at species- or subspecies level as indicated on the IUCN Red List of Threatened Species. A species was considered 'threatened' if classified as either 'Critically Endangered', 'Endangered' or 'Vulnerable'. 'Data Deficient' or 'Near Threatened' species were not considered as threatened in this review.

5. The sex of instrumented animals.

6. The age class of instrumented animals. Here, the use of terms such as 'juvenile' and 'subadult' was not always consistent across papers. I therefore chose to distinguish only between 'adult' and 'immature' animals (where the immature grouping included animals referred to as juveniles, subadults and/or pups).

7. Instrument type deployed (see Table 1 for explanatory detail).

8. The number of animals that carried instruments.

9. The number of instrument deployments resulting in data reported in the paper. This number is referred to as the 'number of successful devices'.

10. The type of outcome reported that resulted from biologging data (see Table 1 for further detail).

11. Whether or not the paper reported explicit resulting applications. Here, I considered as 'applied' those papers that clearly illustrated applications in terms of conservation or management (protected areas, fisheries, etc.). Papers that did not display obvious applications in terms of conservation or management, and papers that made only vague reference to applications (e.g. papers that stated only that the data generated had management/conservation implications but without making explicit recommendations in that regard), were classified as 'non-applied'.

12. The journal where the paper was published.

13. The 5-year Impact Factor (ISI Web of Science) of the journal (or Impact Factor if no 5-year Impact Factor was available).

14. For studies published up to and including 2010, I further recorded the calculated impact of the paper as a function 
of the journal impact factor and the number of citations relative to the year it was published (i.e. impact $=$ journal impact factor + (number of citations / years since publication). Because some papers displayed a lag period whereby citations did not increase linearly over time (unpublished data), I included the journal impact factor in this calculation to provide a more representative indication of impact of recently published papers. I obtained citation numbers obtained from both ISI and Scopus, when available. Only citations recorded up to and displayed during the first two weeks of 2013 (up to and including 14 January) were included. When the citation numbers differed between the two databases, I recorded the higher of the two.

For comparative purposes, I also calculated the impact of a sample of papers making use of biologging data from animals other than marine mammals $(n=40)$. I conducted searches on Scopus using the search phrases 'biologging', 'bio-logging', 'wildlife tracking' and 'telemetry'. The 'telemetry' search was restricted to the research fields of Agricultural and Biological Sciences and Environmental Sciences. From the results for each search phrase, I selected 10 papers published between 1960 and 2010. Selection was done in a systematic fashion; all papers were ordered and numbered by date, before the oldest and youngest papers were selected, followed by eight additional papers separated by equal time intervals.

I investigated the relationships between the calculated impact of papers and other recorded parameters in a number of ways. Impact showed a skewed distribution due to the presence of a number of papers with comparatively high impact (Impact <10: $n=387$; Impact 10-19.9: $n=$ 36; Impact 20-29.9: $n=4$; Impact 30-39.9: $n=4$; Impact 40-49.9: $n=2$; Impact >70: $n=1$ ). I therefore assessed relationships between parameters and the impact of papers at two different levels. Firstly, I investigated relationships between the impact of medium-impact papers (Impact $<10$ ) and parameters using standard parametric statistics (ANOVA, $t$-test and regression). Secondly, I assessed relationships between the frequency of high-impact papers (Impact $\geq 10$ ) and parameters using Fisher's exact test, $\chi^{2}$ tests, and post hoc Marascuilo procedures. Continuous variables were grouped into appropriate categories for assessing their relationships with the frequency of high-impact papers using $k$-means cluster analyses. All statistical procedures were undertaken in the $\mathrm{R}$ programming environment ( $R$ Version 2.15.2; R Core Team 2012) and statistical significance was set at $p<0.05$. Mean and $S D$ values are reported unless otherwise stated.

\section{Results}

\section{Instrumented species}

I recorded a total of 620 papers that used data obtained from biologging instruments deployed on marine mammals between 1965 and 2013 (see Supplementary Material [available online] for complete bibliography). Papers were published in a total of 113 different journals, although four journals accounted for $41 \%$ of all papers published - Marine Ecology Progress Series (75), Marine Mammal Science (68), Polar Biology (62) and Canadian Journal of Zoology (54) (see Supplementary Figure S1 [available online]).

Data obtained from deployments on phocids were most often reported (in 355 papers), followed by data from otariids (190), odontocetes (101), mysticetes (51), polar bears (13), sirenians (8), odobenids (7) and sea otters (5). The sum of these papers (730) exceeded the total number of papers considered (620) because several papers reported data from multiple families and/or suborders.

Within the group of papers reporting data from biologging instruments deployed on phocids, $80 \%$ reported results obtained from the five species most often used to carry devices (southern elephant seals Mirounga leonina; Weddell seals Leptonychotes weddellii; northern elephant seals Mirounga angustirostris; harbour seals Phoca vitulina; and grey seals Halichoerus grypus) (Figure 1a). Among the Otariidae, Antarctic fur seals Arctocephalus gazella were by far the most often reported as study species, followed by northern fur seals Callorhinus ursinus, New Zealand sea lions Phocarctos hookeri, Steller sea lions Eumatopias jubatus, and California sea lions Zalophus californianus (Figure 1b). Blue- Balaenoptera musculus, humpback- Megaptera novaeangliae, fin- Balaenoptera physalus and bowhead whales Balaena mysticetus were most often reported to carry biologging instruments among mysticetes (Figure 2a). Narwhals Monodon monoceros,

Table 1: Summary information regarding the instrument type and outcome reported as recorded for each paper

\begin{tabular}{ll}
\hline Parameter & Levels/groupings (one, or any combination) \\
\hline Instrument type & Acoustic (environmental acoustics and/or acoustics emanating from the tagged animals) \\
& Camera (still or video imagery) \\
& Environment (in situ measures of temperature, conductivity and/or fluorescence) \\
& Physiological (e.g. heart rate, body temperature, electrocardiogram [ECG], etc.) \\
& Dive behaviour (e.g. time-depth recorders, accelerometers, speed sensors, etc.) \\
& Location (e.g. platform transmitting terminal [PTT], global positioning system [GPS], geolocation, etc.). Very-high- \\
& frequency (VHF) transmitters were considered only if used for tracking purposes, and not for device retrieval \\
\hline Outcome reported & Acoustics \\
& At-sea dive behaviour (e.g. time-depth profiles, travel speed, etc.) \\
& At-sea location information \\
& Device influence (e.g. on behaviour, condition or survival of study animals, or other ecological impacts) \\
& Method (e.g. statistical analyses, tag technological improvements, etc.) \\
& Oceanography \\
& Physiology
\end{tabular}


belugas Delphinapterus leucas and sperm whales Physeter macrocephalus were most often used to carry biologging instruments among odontocetes, together resulting in $41 \%$ of all papers reporting results from odontocetes (Figure 2b). Of all papers assessed, 144 reported results obtained from species classified as threatened by the IUCN Red List. Of these, five papers included results from Critically Endangered species, 52 from Endangered species and 86 from Vulnerable species.

All pinniped species, except for one otariid- and two phocid species, were represented in the dataset (see Supplementary Table S1 [available online]). I did not find any papers resulting from biologging deployments on Arctocephalus phillippii (Juan Fernández- A. philippii phillippii or Guadalupe fur seals A. p. townsendi). Neither did I find any papers reporting biologging results from Caspian seals Pusa caspica, nor ribbon seals Histriophoca fasciata. Cetaceans were less well represented and I found data reported from deployments made on only 31 species of cetaceans out of a potential 90 currently recognised species (see Supplementary Table S1). The trend in numbers of papers published per year showed an exponential increase, starting in the early 1990s (Figure 3).

\section{Spatial distribution of deployments}

Results were reported from biologging deployments made in close proximity to all continents and showed a wide distribution (Figure 4). The distribution included the coastlines of all continents, and many island groups with high densities are evident along the east and west coasts of North

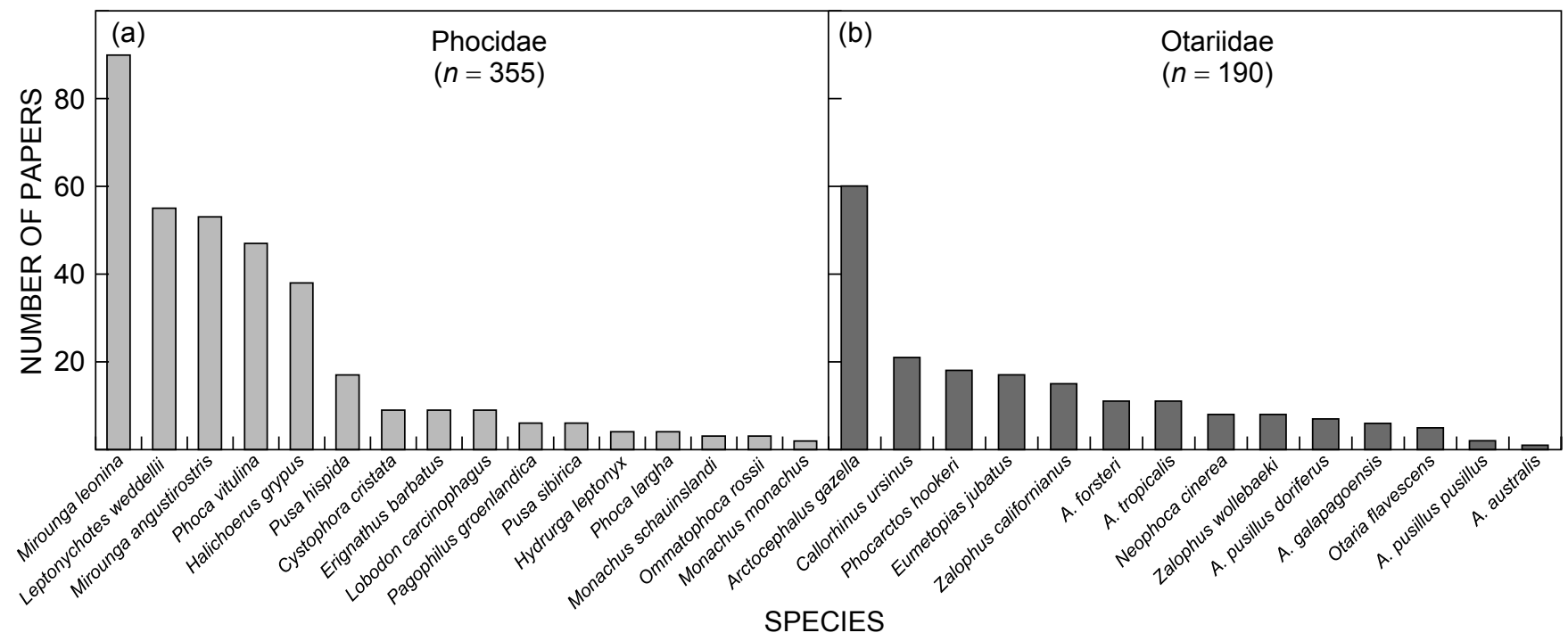

Figure 1: Number of papers resulting from biologging deployments on individual species of (a) Phocidae and (b) Otariidae

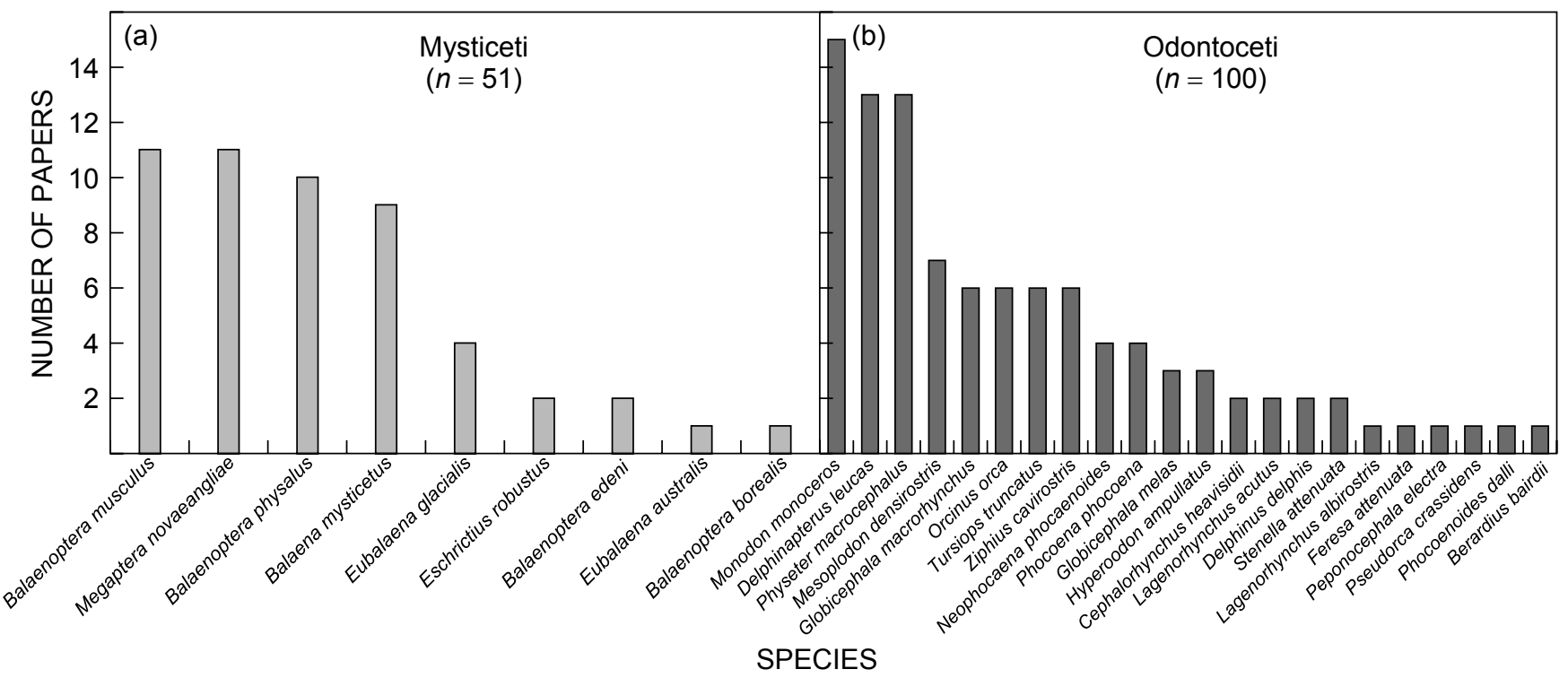

Figure 2: Number of papers resulting from biologging deployments on individual species of (a) Mysticeti and (b) Odontoceti 
America, as well as north-western Europe. Other areas where high numbers of papers reported results include the western Antarctic Peninsula, eastern Australia and many of the sub-Antarctic islands. I found no papers that reported biologging results from deployments made on the east coast of Africa, the Middle East, southern Asia, or the west coast of South America.

\section{Applied vs non-applied}

I classified $15.3 \%$ of all papers as applied. Papers resulting from deployments on threatened species had a higher likelihood of being classified as applied than studies that involved deployments on species not considered threatened $\left(\chi^{2}=26.23, \mathrm{df}=1, p<0.001\right)$. There was no significant difference in impact between applied papers and those classified as non-applied (Wilcoxon test: $W=11379, p=$ $0.85)$. An increasing trend in the proportion of papers classified as applied from the mid-1990s was evident, and these made up $29 \%$ of all biologging papers on free-ranging marine mammals recorded for 2013 (Figure 5).

\section{Age- and sex classes}

Most papers reported results obtained from deployments made only on adult animals $(n=272)$, followed by a combination of adults and immature animals $(n=98)$ and then immature animals only $(n=95)$. Results obtained from

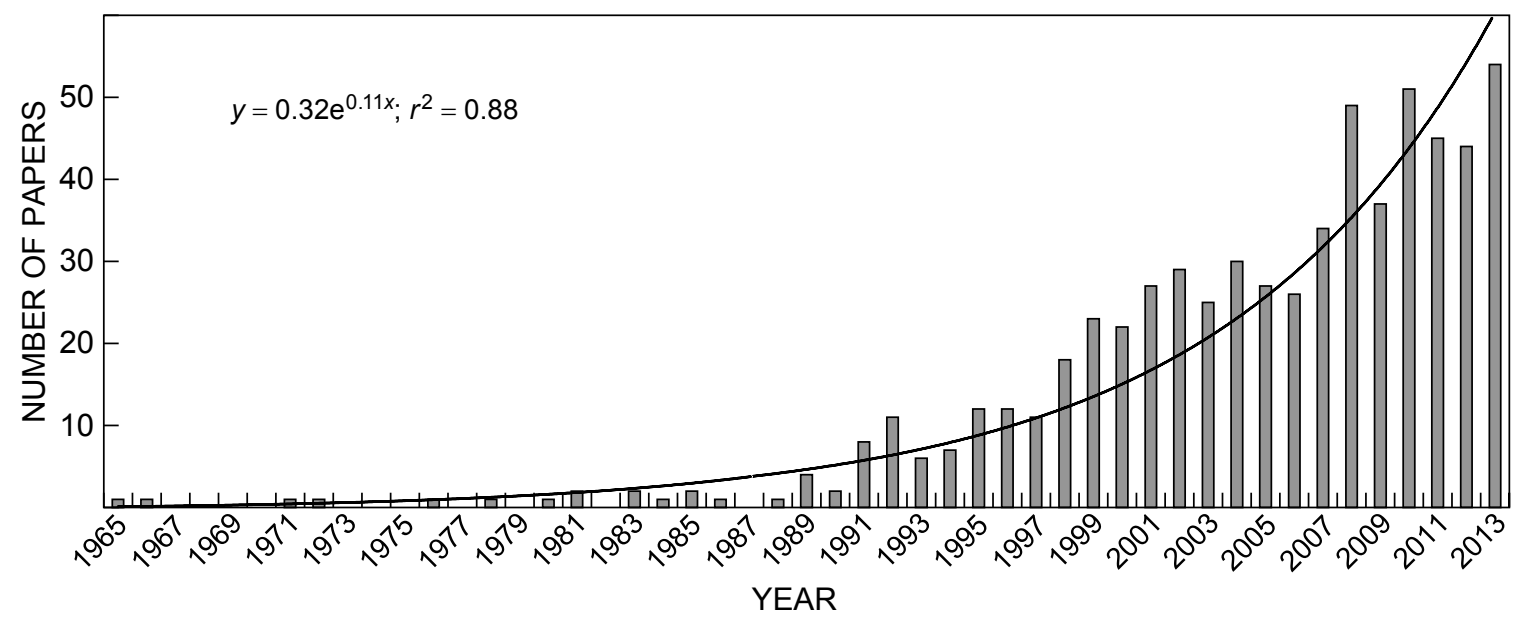

Figure 3: Exponential trend over time in number of papers that reported results obtained from biologging deployments on free-ranging marine mammals, 1965-2013

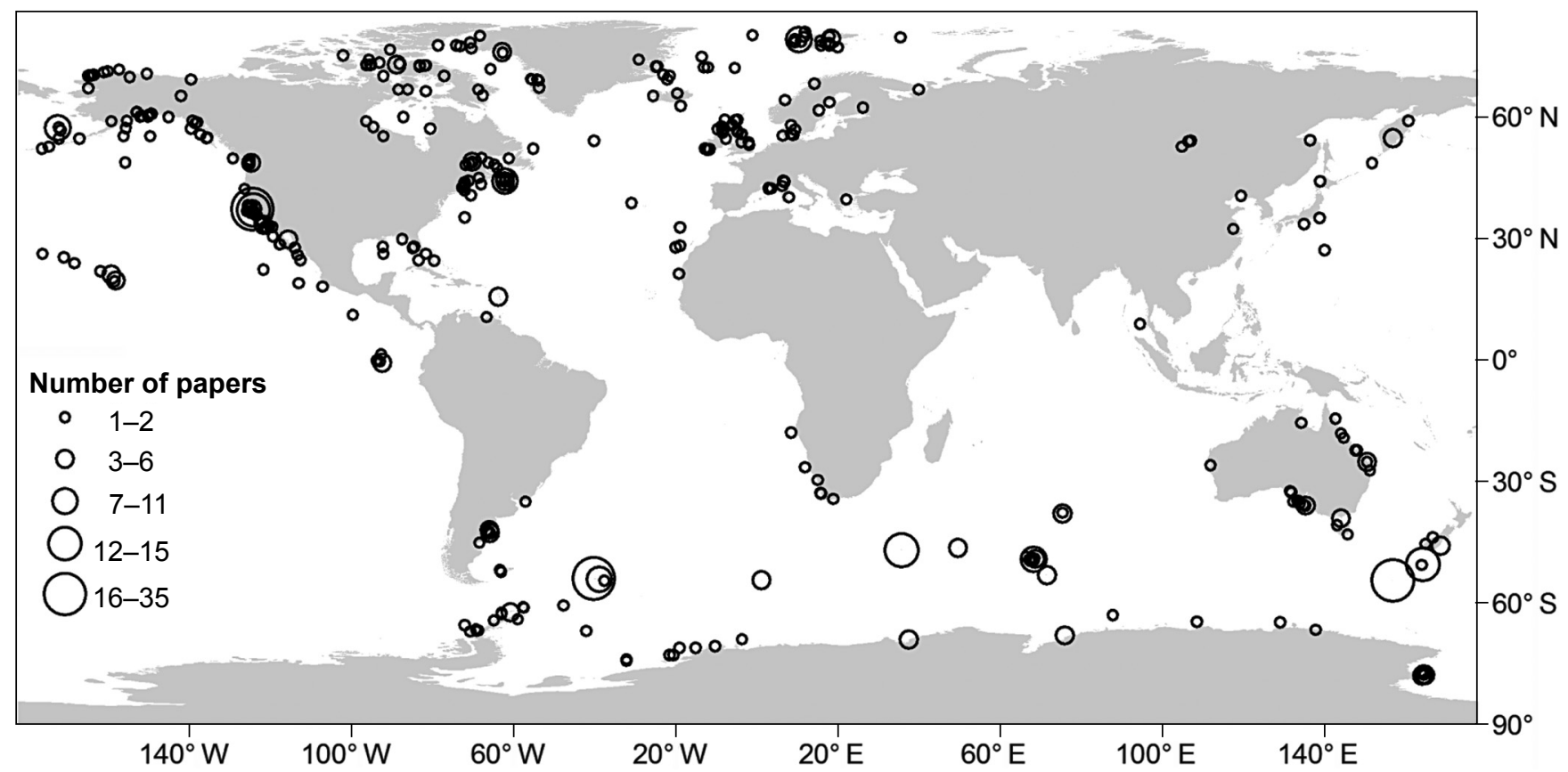

Figure 4: The number of papers per approximate location of reported biologging deployments on free-ranging marine mammals (1965-2013) 
deployments made only on female animals were reported in 217 papers, whereas 54 papers resulted from deployments made only on male animals, and 233 from deployments made on animals of both sexes. Among papers that reported results from adult animals $(n=355)$, there was significant bias in favour of females, with fewer papers reporting results from adult males $(n=126)$ than would have been expected from a 50:50 ratio $\left(\chi^{2}=11.68, p<\right.$ 0.001).

\section{Impact}

The mean impact of all papers assessed was 6.3 (SD 6.1; median $=5$ ). I found no trend over time in the impact of papers $\left(y=-0.08 x+157 ; r^{2}=0.004, F_{1,430}=2.63, p=0.12\right)$. Similarly, when considering medium-impact papers alone, no trend in impact was evident over time $(y=0.01 x-7.8$; $\left.r^{2}=-0.002, F_{1,383}=0.14, p=0.71\right)$. However, there was an increase in the frequency of high-impact papers over time (Figure 6). The mean impact of the 40 papers examined that used biologging data from animals other than marine mammals was 6.3 (SD 7.4; median $=4.9)$ and did not differ significantly from marine mammal papers $(W=8104, p=$ 0.516).

\section{Numbers of species}

Most papers reported results from biologging deployments on a single species (single species, $n=572$; multiple species, $n=48$ ), and the maximum number of species included in a paper was 17 . Medium-impact papers resulting from deployments on multiple species did not have a different impact compared to single-species papers $(W=$ $3238.5, p=0.137$ ). However, papers reporting results from multiple species showed a higher frequency of high-impact papers compared to single-species papers (Fisher's exact test: odds ratio $=4.44, p<0.001$ ).

\section{Numbers of devices deployed}

Where reported, the median number of devices deployed in studies was 15 (range: 1-297). The median number of successful devices was 12 (range: 1-509). Various papers

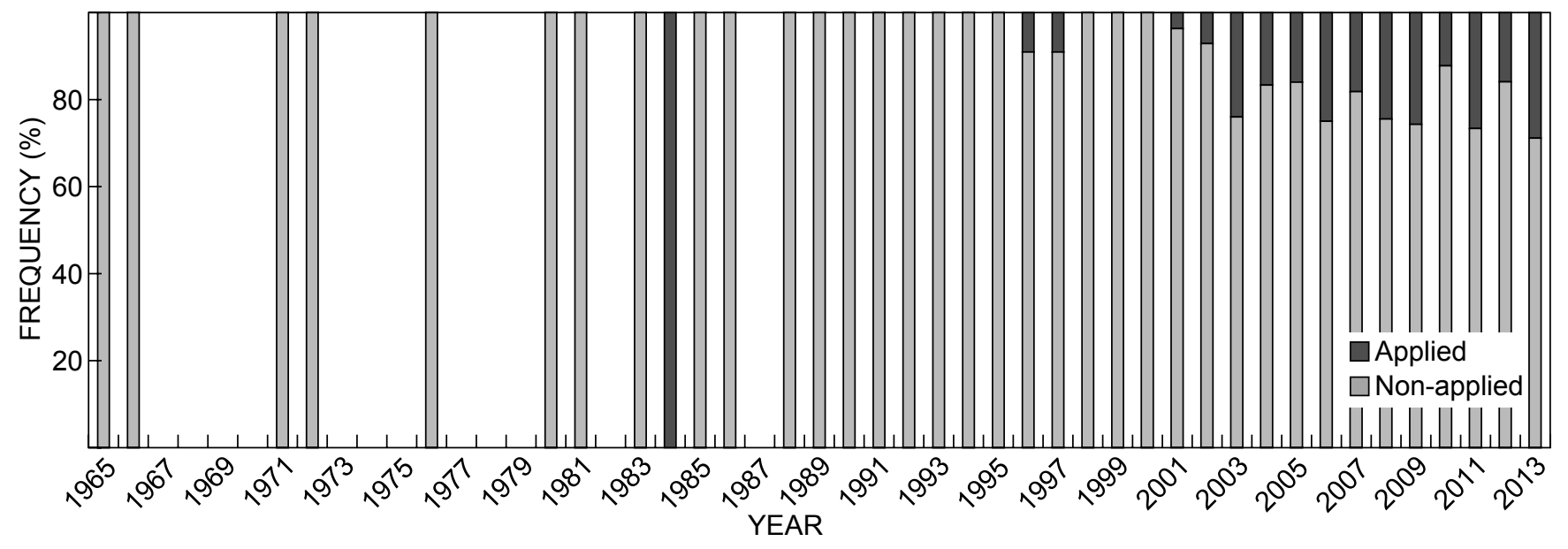

Figure 5: Variation over time in the proportions of applied and non-applied marine mammal biologging papers, 1965-2013

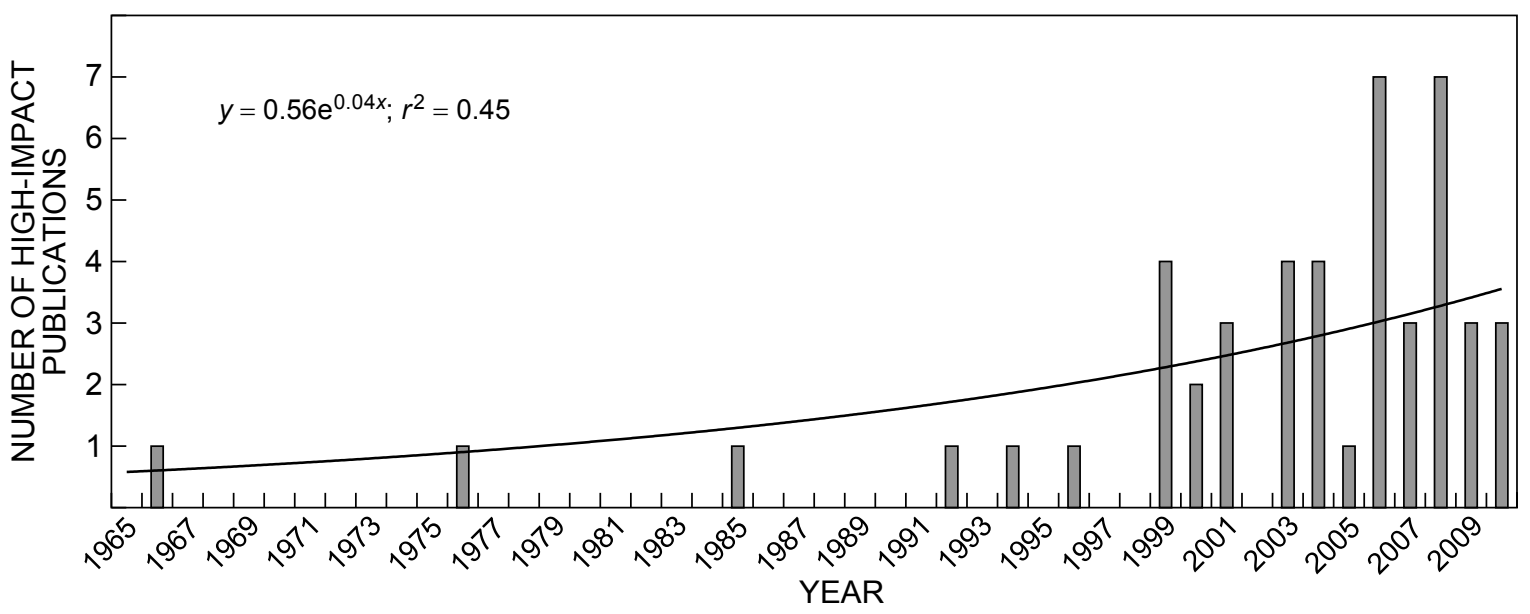

Figure 6: Exponential trend over time in number of high-impact papers that resulted from biologging deployments on marine mammals, 1965-2010. High-impact papers were defined as papers with impact values $\geq 10$ 
reported only one or other of these quantities, which explains why the upper range limit of the former was lower than that of the latter. There was an increasing trend over time in both the number of devices deployed $(y=1.01 x-$ $\left.2003 ; r^{2}=0.03, F_{1,441}=14.44, p<0.001\right)$, as well as the number of successful devices $\left(y=1.03 x-2036 ; r^{2}=\right.$ $\left.0.02, F_{1,488}=11.14, p<0.001\right)$ (Supplementary Figure S2 [available online]).

There were weak, but significant, positive relationships between the impact of medium-impact papers and the number of devices deployed $\left(y=0.02 x+4.37 ; r^{2}=0.07\right.$, $\left.F_{1,312}=22.7, p<0.001\right)$, as well as the number of successful devices $\left(y=0.01 x+4.59 ; r^{2}=0.03, F_{1,332}=12.7, p<0.001\right)$.

There was a significant difference in the frequencies of high-impact papers between identified clusters of the numbers of deployed devices $\left(\chi^{2}=21.07, \mathrm{df}=3, p<0.001\right)$. The post hoc Marascuilo procedure revealed a significantly higher frequency of high-impact papers among papers reporting on 51-120 deployed devices, when compared to other clusters (Table 2). Similarly, there was a significant difference in frequencies of high-impact papers between identified clusters of the numbers of successful devices $\left(\chi^{2}=23.05, \mathrm{df}=3, p<0.001\right)$. The cluster of papers reporting on data from 38 to 86 deployments had a significantly higher frequency of high-impact papers, when compared to clusters with fewer deployments (Table 2). I detected no significant difference in the frequency of high-impact papers between the cluster of 38-86 deployments and the cluster containing papers reporting data from more than 86 devices.

\section{Instrument types}

Instrument types (or combinations of instrument types) deployed were most often capable of providing both spatial location as well as some type of dive behavioural data (e.g. time-depth information) $(n=210)$. This was followed by deployments capable of returning location information only $(n=182)$; dive behavioural data only $(n=$

Table 2: Results from post hoc Marascuilo procedures on the frequencies of clusters of high-impact papers. Papers were grouped according to reported numbers of instrument deployments (clusters identified by $k$-means clustering)

\begin{tabular}{|c|c|c|c|}
\hline $\begin{array}{l}\text { Cluster (number of } \\
\text { devices) }\end{array}$ & $\begin{array}{c}\text { High-impact } \\
\text { papers (\%) }\end{array}$ & Comparison & Significance \\
\hline \multicolumn{4}{|c|}{ Devices deployed } \\
\hline $\mathrm{C} 1(n=1-18)$ & 5.97 & $\mathrm{C} 2: \mathrm{C} 4$ & ns \\
\hline $\mathrm{C} 2(n=19-50)$ & 6 & $\mathrm{C} 1: \mathrm{C} 2$ & ns \\
\hline C3 $(n=51-120)$ & 29.41 & C2:C3 & $p<0.05$ \\
\hline \multirow[t]{3}{*}{ C4 $(n>120)$} & 0 & C1:C3 & $p<0.05$ \\
\hline & & $\mathrm{C} 1: \mathrm{C} 4$ & $p<0.05$ \\
\hline & & C3:C4 & $p<0.05$ \\
\hline \multicolumn{4}{|c|}{ Devices returning data used for paper } \\
\hline $\mathrm{C} 1(n=1-13)$ & 8.25 & $\mathrm{C} 1: \mathrm{C} 2$ & ns \\
\hline $\mathrm{C} 2(n=14-37)$ & 6.3 & $\mathrm{C} 2: \mathrm{C} 4$ & ns \\
\hline C3 $(n=38-86)$ & 32.56 & C1:C4 & ns \\
\hline \multirow[t]{3}{*}{$\mathrm{C} 4(n>86)$} & 20 & C3:C4 & ns \\
\hline & & C1:C3 & $p<0.05$ \\
\hline & & $\mathrm{C} 2: \mathrm{C} 3$ & $p<0.05$ \\
\hline
\end{tabular}

ns $=$ not significant
125); or a combination of spatial, behavioural and in situ environmental data $(n=56)$. All other instrument types (or combinations) were used in $<20$ papers. Numbers of papers using instruments capable of providing location information (also in combination with behavioural data, as well as in combination with behavioural and environmental data) showed an increasing trend over time (Figure 7). However, the sole use of instruments capable of obtaining only dive behavioural data showed a peak between 1998 and 2001, and appears to be decreasing (Figure 7).

A type-II ANOVA revealed a statistically significant difference in impact between papers reporting results from the various instrument-type categories $\left(F_{5,404}=3.81\right.$, $p=0.002$ ). A multiple comparisons test (Tukey contrasts, implemented using the multcomp package - Hothorn et al. [2008]) revealed that papers using instruments capable of providing only spatial location data had significantly lower impact than papers using instruments (or combinations of instruments) capable of providing spatial location and dive behavioural data (Figure 8). Papers that used instruments capable of also recording in situ environmental variables (in addition to spatial and behavioural data) also had significantly higher impact than papers using spatial location only data (Figure 8). There were no other significant differences in impact between instrument types. I found no evidence for differences in the frequency of high-impact papers between papers reporting from the six instrument-type categories most often reported $\left(\chi^{2}=9.82, \mathrm{df}=5, p=0.08\right)$.

\section{Outcome type}

Papers that included animal behaviour (see Table 1 for definitions) outcomes were most numerous $(n=382)$ followed by papers that reported spatial movement outcomes $(n=325)$, methods $(n=67)$, oceanography $(n=25)$, physiology $(n=24)$ and device influence (14). Eight papers addressed device influence on pinnipeds (e.g. Heaslip and Hooker 2008; McMahon et al. 2008; Field et al. 2012), whereas six addressed device influence on cetaceans. Papers addressing device influence on cetaceans mostly reported only immediate behavioural responses to deployments (e.g. Watkins 1981; Watkins and Tyack 1991; Hanson and Baird 1998; Schneider et al. 1998), whereas one paper reported tissue healing around attachment sites (Sonne et al. 2012) and one reported on the survival of tagged individuals (Mizroch et al. 2011). I found no evidence for differences in the impact of medium-impact papers between types of outcome reported (ANOVA: $F_{11,373}=1.7, p=0.07$ ). Also, there was no evidence for an influence of outcome type on the frequency of high-impact papers $\left(\chi^{2}=4.65, \mathrm{df}=5, p=0.46\right)$.

\section{Discussion}

\section{Which marine mammals are instrumented?}

This review illustrates firstly the dramatic increase since the 1990s in the number of scientific papers resulting from biologging deployments on marine mammals. Given the technological advances in biologging instruments of this time period (Ropert-Coudert and Wilson 2005; Evans et al. 2013), this outcome is not surprising. The distribution of biologging papers was biased firstly towards pinnipeds, 


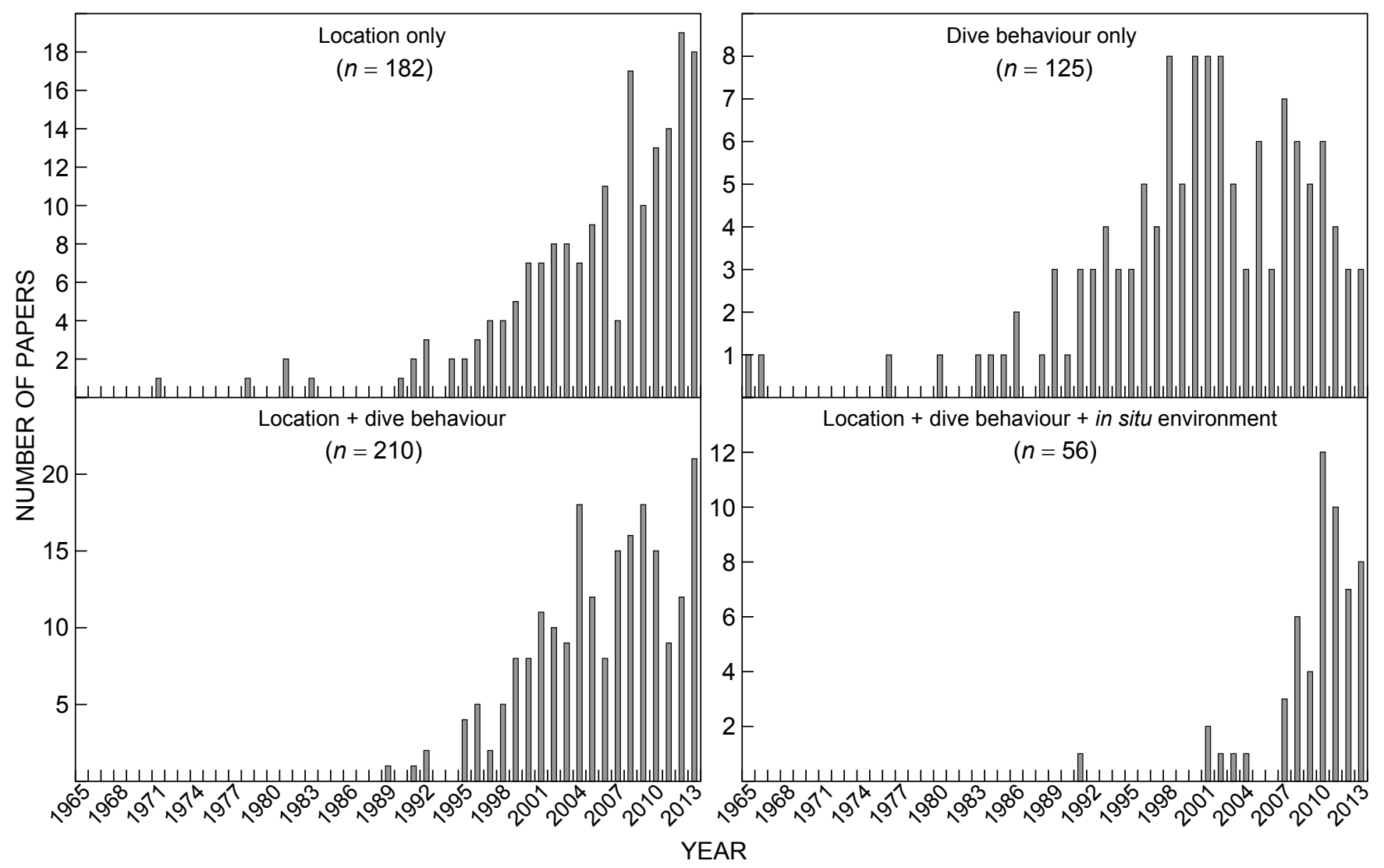

Figure 7: Variation over time in number of publications that reported results according to instrument type and/or combination of instrument type used, 1965-2013

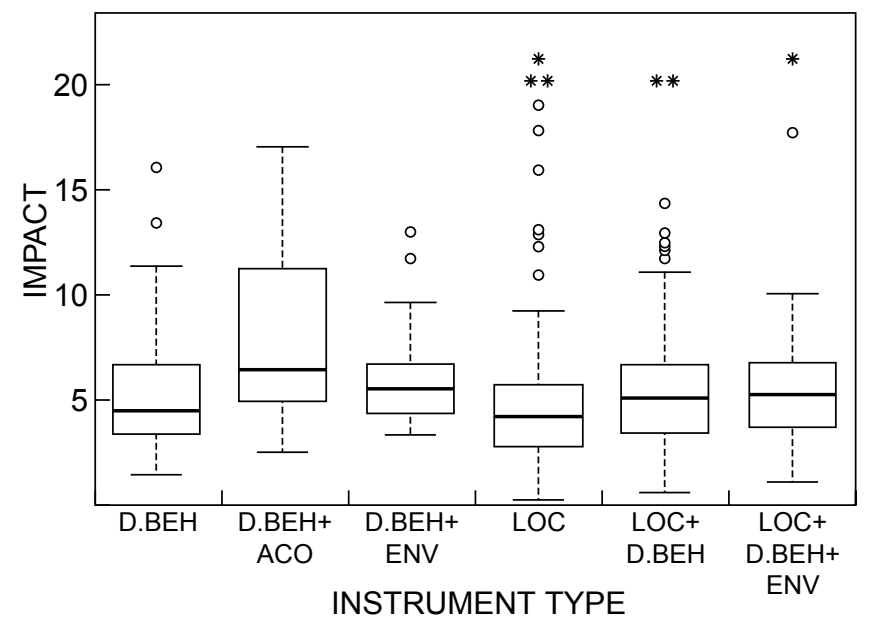

Figure 8: Box-and-whisker plot indicating differences in impact of medium-impact papers between instrument types used. D.BEH = dive behaviour only; D.BEH+ACO = dive behaviour + acoustics; $\mathrm{D} . \mathrm{BEH}+\mathrm{ENV}=$ dive behaviour + in situ environment; $\mathrm{LOC}=$ spatial location only; $\mathrm{LOC}+\mathrm{D} . \mathrm{BEH}=$ spatial location + dive behaviour; LOC+D.BEH+ENV = spatial location + dive behaviour + in situ environment. Bold line $=$ median, box $=25$ th and 75 th percentiles, points $=$ outliers, whiskers $=1.5$ times the interquartile range, or the maximum value (when there are no outliers). Statistical significance is indicated as follows: ${ }^{*} p \leq 0.05,{ }^{* *} p \leq 0.005$ and secondly to a comparatively small number of species (specifically southern elephant seals and Antarctic fur seals). The distribution of biologging papers on marine mammal groups other than the Phocidae and Otariidae (walruses, cetaceans, polar bears and sea otters) was more even, with 13 species each presented in six or more papers, whereas 22 species contributed to the remaining 51 papers. An earlier review of tracking and dive behaviour studies of marine mammals suggested that only $13.3 \%$ of the available data were generated by cetaceans (Shaffer and Costa 2006). While the current review still indicates a comparative paucity in biologging studies on cetaceans (particularly when considering the higher diversity of cetaceans compared with pinnipeds), it also suggests a relative increase in the study effort on cetaceans through the use of biologging during the past eight years. A major limitation in the use of biologging instruments on cetaceans has been attachment techniques (Hooker and Baird 2001). These obvious additional difficulties in locating and attaching devices to exclusively aquatic marine mammals (compared with marine mammals that haul out onto land) explains the differences in numbers of publications between the seals and groups such as the cetaceans. Current attachment techniques for cetaceans include the use of stainless steel barbs designed to penetrate the blubber of study animals (e.g. Minimikawa et al. 2007; Andrews et al. 2008) or potentially less-invasive suction-cups for 
shorter-term deployments (e.g. Amano and Yoshioka 2003; O'Malley Miller et al. 2010). Scientists generally rely on either capturing smaller cetaceans (e.g. Lydersen et al. 2002) or remotely deploying instruments using tagging poles (e.g. Davis et al. 2007), cross-bows (e.g. Mate et al. 2011), firearms (e.g. Tyack et al. 2011) or air guns (Heide-Jørgensen et al. 2001). Whereas the practicality, effectiveness and safety of available attachment techniques seems to remain a challenge, the increasing trends in publications for Odontoceti and Mysticeti suggest that these limitations are being overcome.

Among the pinnipeds, elephant seals are considered ideal animals to carry biologging instruments, given their large size (Le Boeuf and Laws 1994), long-distance migrations (Hindell and McMahon 2000; Mclntyre et al. 2011b), extreme dive behaviour (Mclntyre et al. 2010a) and high fidelity to haulout locations (Hofmeyr et al. 2012). It is therefore not surprising that so many studies have used elephant seals to carry biologging instruments. The high number of papers on Antarctic fur seals largely emanates from intensive study efforts carried out at Bird Island, South Georgia (e.g. Boyd et al. 1995; Staniland et al. 2007), and the Kerguelen Islands (e.g. Bonadonna et al. 2001; Lea et al. 2002).

Biologging instrument deployments were heavily biased towards adult female animals, and the results reported here illustrate the relative paucity of biologging data obtained from immature animals, as well as adult males. A similar bias has been described for satellite telemetry data specifically from pinnipeds (Hart and Hyrenbach 2009) and attributed to both ecological and logistical biases. For example, female central-place foragers tend to return reliably to land in order to attend to nursing pups (Hoelzel 2009), whereas (larger) male animals tend to be less predictable and can be more difficult to immobilise safely for instrument deployments (Ramdohr et al. 2001; Geschke and Chilvers 2009). Such bias in information in favour of one demographic group provides obvious limits to interpretation of data pertaining to the behaviour of the instrumented species, particularly in the many species that exhibit sexual- and/ or age-related segregation in behaviour and habitat use patterns (e.g. Field et al. 2005; Mclntyre et al. 2010b; Leung et al. 2012).

\section{Instrument types}

Instrument types (or combinations thereof) used in the studies assessed here most often provided location and dive behavioural data. These were often combinations of satellite transmitters and time-depth recorders. Time-depth recorders were among the first instruments used in animalborne deployments on marine mammals (Kooyman 1965). Such recorders are still in use in many studies (e.g. Bodkin et al. 2012; Dragon et al. 2012b), although instrument sizes have decreased relative to early models, storage capacities have increased and sensor accuracies have improved. The use of satellite-linked instruments to obtain location data is comparatively new (compared to logging instruments such as time-depth recorders), and some of the first studies to make use of such technology on free-ranging marine mammals were published in the late 1980s/early 1990s. These studies include the tracking of harbour seals in the 1980s (e.g. Stewart et al. 1989), grey-, ringed- and elephant seals in the early 1990s (e.g. Heide-Jørgensen et al. 1992; McConnell et al. 1992a, 1992b) and bottlenose dolphins in the early 1990s (e.g. Mate et al. 1995). Satellitelinked instruments traditionally used Service Argos to obtain location estimates. This technology is now often combined with, or even replaced by, the use of GPS technology to obtain more-accurate position estimates for tracked marine mammals (e.g. Costa et al. 2010; Dragon et al. 2012b).

The continuing increase of papers that report data from devices that provide only spatial data can mostly be attributed to the increasing number of papers that report results from satellite tags deployed on cetaceans. For example, of the 22 papers using location-only instruments published in 2012, 11 resulted from deployments on cetaceans (e.g. Gales et al. 2012; Lydersen et al. 2012; Woodworth et al. 2012). This trend can be expected to change in the future, as improvements in attachment techniques and decreased instrument sizes will allow for the incorporation of additional sensor packages on devices suitable for cetacean deployments (e.g. Laidre et al. 2010), resulting in the replacement of location-only instruments with location/ dive behaviour- and location/dive behaviour/in situ environmental instruments.

My interpretation of the prevalence of various instrument types is likely to contain some bias due to authors not reporting the full capabilities of instruments deployed. For instance, whereas modern time-depth recorders often also measure in situ water temperature, this capability was not necessarily mentioned if the authors reported results of the time-depth data only. I therefore expect, for example, that the trend in papers using dive behaviour-only instruments (Figure 7) may be an under-representation of the decline in use of dive behaviour-only instruments. Similarly, the increase of papers reporting data obtained from devices capable of also measuring in situ environmental variables (Figure 7) is likely to be more pronounced than is reported here.

\section{Scientific impact}

The impacts of marine mammal biologging papers were very similar to those of biologging papers resulting from other taxa. Despite the rapidly increasing numbers of publications, there was no clear trend in the impact of papers over time, other than an increasing frequency of high-impact papers. This stability in impact may be due to consistency of overall quality and visibility of papers, or alternatively to the increasing numbers of papers themselves sustaining impact levels of other marine mammal biologging papers through citations (i.e. through a positive feedback). The results reported here suggest that the impact of papers is influenced by numbers of species studied, sample sizes, and to a limited extent the capabilities of devices used.

The influences of number of species and sample size on the impacts of papers were not surprising. Papers that reported data from multiple taxa tended to be either: (1) of broad relevance to entire ecosystems (e.g. Block et al. 2011); (2) fundamental to the understanding of movement and behavioural traits (e.g. Sato et al. 2007; Sims et al. 2008; Watanabe et al. 2011); (3) of a comparative nature (e.g. Schreer et al. 2001); or (4) illustrative of 
broadly-applicable methods (e.g. Freitas et al. 2008). The likely influence of larger sample sizes on the citation frequency of papers has previously been acknowledged (Padial et al. 2010), and furthermore is illustrated for medical papers (Kostoff 2007). These results therefore highlight the influence of sample size on the impact of papers, even when sample size ranges are within ranges typical for ecological studies.

\section{Addressing possible adverse instrument effects}

I recorded only 14 papers with explicit aims to address instrument and/or instrument deployment influences on the study animals and/or the marine environment. This includes only those papers with assessment of deployment influences as a central aim, and not necessarily all papers that incidentally reported such an influence (or lack thereof). I also excluded papers reporting results from captive environments or papers based on modelling exercises solely; the inclusion of such papers (e.g. Pavlov et al. 2007) and other unpublished research (e.g. Hanson 2001) would have increased the number of papers addressing device influences on animals. The need for more studies assessing device impacts has also been recognised by other authors (Wilson and McMahon 2006; Hart and Hyrenbach 2009; McMahon et al. 2011). Godfrey and Bryan (2003) reported - from an analysis of radio-tracking papers of various taxa - that only $4.5 \%$ of mammal studies (including terrestrial mammals) explicitly assessed tag effects on study animals. Interestingly, $61 \%$ of these studies reported substantial tagging effects, thereby further illustrating the need for more information on potential tagging impacts. McMahon et al. (2011) summarised potential negative effects of biologging devices either in association with capture (e.g. stress, anaesthesia side-effects, etc.), device types (e.g. inducing drag, attracting predators, etc.), attachment method (e.g. generation of excessive heat by glues) or timing/duration of attachment (which may have an influence during breeding seasons, etc.). Nevertheless, whereas some assessments have shown no consequences of instrument attachment in terms of long-term survival (e.g. McMahon et al. 2008), the results of this review illustrate a paucity of studies quantifying the influences of biologging devices on the energetics, fitness and survival of free-ranging animals that are used to carry instruments. This field of investigation, therefore, apparently remains an important one that requires more focus in order to ensure the ethical use of biologging instruments.

\section{Outcomes and subject categories - are researchers optimising the output generated?}

Papers mostly reported outcomes that were classified either as animal dive behaviour or spatial movement. Similarly, Hart and Hyrenbach (2009) reported that the largest proportions of papers resulting from satellite tracking of marine mammals focused on the movements and habitats of animals, with other topics addressed in fewer papers. The dominance of behaviour and spatial movement papers mirrors the use of instrument types, which were dominated by devices capable of recording this type of information.

Although not explicitly reflected in the results, single datasets were frequently used to produce various papers, whereby authors either used different methods to analyse data or used previously collected data to address new questions. Furthermore, a number of papers assembled various datasets in order to answer questions related either to various species (e.g. Sims et al. 2008; Watanabe et al. 2011), areas used by multiple animals (e.g. Block et al. 2011) or inter-population differences in behaviour (e.g. James et al. 2012). McMahon et al. (2011) advocated the so-called 'three Rs' in biologging studies, suggesting that researchers should: (1) reduce the numbers of animals instrumented (although maintaining statistically relevant numbers); (2) refine procedures to minimise pain and stress; and (3) replace experiments involving animals with in vitro models as far as possible. I suggest the inclusion of a 'fourth R', namely recycling of available data. Of course, technological improvements allow for answering new questions, and therefore require new deployments of suitable instruments, and in some cases ongoing deployments of appropriate devices are pursued in the context of long-term monitoring programmes (e.g. Bester et al. 2011). However, there is a substantial amount of marine mammal biologging data among researchers across the world that could support new research.

Shaffer and Costa (2006) suggested the need for a common repository where marine mammal tracking- and dive behaviour data can be stored and made available for wider use within the marine mammal community. Efforts to store data appropriately and make them more widely available have been ongoing during recent years and are the subject of various online initiatives (e.g. Australian Antarctic Data Centre [https://data.aad.gov.au/]; PANGAEA [Diepenbroek et al. 2002]; SCAR-MarBIN [http://www. scarmarbin.be/index.php]). This review, and the associated bibliography (see online Supplementary Material), aims to increase further the awareness of data already collected by marine mammal researchers, as well as other scientists (e.g. oceanographers) who are interested in using data obtained from biologging instruments on marine mammals. An increased awareness of the data that have been collected, coupled with appropriate data storage and increased data availability, can not only assist in answering additional interesting questions, but can also reduce the need for additional deployments.

\section{Biologging and conservation/management}

Marine mammals are a comparatively poorly known group, facing high threat levels (Schipper et al. 2008), and biologging studies have the potential to inform numerous conservation and management actions. The potential benefits of using biologging instruments in animal conservation research are many (see review by Cooke 2008). These include the potential to inform assessments of animal distributions, emigration behaviour, reproductive potential, mortality rates, and habitat use. The results presented here show that biologging deployments have been concentrated at higher latitudes, particularly along the North American and northern European coastlines, as well as the sub-Antarctic islands and the Antarctic continent (Figure 4). This is similar to the distribution reported by Shaffer and Costa (2006), who noted a paucity of marine mammal tracking- and dive behaviour studies in mid-latitudes, and 
closer to the equator. Whereas high numbers of globally threatened marine mammal species occur at high northern latitudes, the distributions of data-deficient species, as well as those threatened by accidental mortality (e.g. fisheries interactions, etc.) are concentrated at the equator and mid-latitudes (Schipper et al. 2008). This indicates a substantial spatial mismatch, with the exception of the Australian coastline, between the general use of biologging technologies on marine mammals and the spatial areas where such information is most likely to inform conservation and/or management actions. Furthermore, only a small proportion of studies reported explicit conservation and/ or management implications (15.3\%), despite numerous papers stating that their results have either management or conservation implications, but without providing specific detail. This proportion did show signs of a clear increase over time, however, from the early 2000s onwards. Two caveats associated with the interpretation of these data, as well as the lack of papers on a number of species (see below), are (i) the exclusion of literature other than peer-reviewed journal articles and (ii) the possible omission of relevant peer-reviewed literature in languages other than English. I excluded from the review documents that formed part of the so-called 'grey literature' (e.g. policy documents, reports, etc.), and the inclusion of such documents would likely have increased the number of cases where biologging information has been applied in conservation and management actions.

I did not find any publications resulting from biologging deployments on Juan Fernandez fur seals, Guadalupe fur seals, Caspian seals or ribbon seals. However, biologging investigations have been undertaken on at least some of these species without resulting in (English language) peer-reviewed papers (e.g. Osman 2008). All of these species are potentially of some conservation concern - both fur seal species are currently listed as Near Threatened on the IUCN Red List, Caspian seals as Endangered and ribbon seals as Data Deficient. Caspian seal populations have experienced decreases exceeding $70 \%$ over the past three generations, apparently due to excessive hunting (Harkonen et al. 2008), disease outbreaks (Kuiken et al. 2006), and possible negative effects associated with environmental contaminants (Watanabe et al. 1999). I further did not find biologging papers on a number of threatened cetacean species. Examples here include the Critically Endangered vaquita Phocoena sinus and the Endangered Ganges river dolphin Platanista gangetica. Although conservation science could potentially benefit from reliable habitat-use information from animal-attached devices, difficulty in the deployment of such devices on timid animals such as vaquitas is acknowledged (Morrel 2008). In such cases, alternative technologies are increasingly being used to obtain population and movement estimates of animals (Dalton 2008; SasakiYamamoto et al. 2013).

Overall, the results presented here suggest that a comparatively small proportion of biologging studies on marine mammals are clearly of an applied nature, despite the non-specific claims of many papers to the contrary, and that the use of biologging technologies is still underrepresented in conservation and management science. There is therefore a need to further develop study designs to deliver research outputs useful to marine mammal conservation practitioners and other decision makers. This accords with the suggestions of others to increase the applicability of conservation-related research for the advancement of specific conservation goals (e.g. Laurance et al. 2012).

In conclusion, numbers of scientific papers resulting from the deployment of biologging instruments on marine mammals are increasing rapidly. This review has illustrated how such papers are distributed between species, geographical areas, instrument types, journals and outcome categories. The scientific impact of marine mammal biologging papers appears to be relatively stable, although increases in the number of very high-impact papers are evident. There is a clear bias, with regard to species, age class and sex, in terms of data reported and this can be expected to limit the inferences obtainable from the available data. This review has also identified a paucity both of biologging papers with explicit management and/or conservation implications, and of papers aiming to quantify instrument deployment influences on study animals and their environments. It is hoped that the review will increase awareness of existing biologging data from marine mammals, encourage additional use of such data (e.g. through meta-analyses) and lead to the increased application of biologging studies for conservation and management purposes.

Acknowledgements - I thank Natalie Haussmann for providing comments on an earlier version of the manuscript. I also thank David Janiger for substantial assistance with tracking down some older, and slightly more obscure, papers. Comments from two anonymous reviewers improved the manuscript. I was supported by an Alexander von Humboldt Foundation Fellowship, as well as a research fellowship from the University of Pretoria, during various stages of manuscript preparation, and wish to particularly thank Horst Bornemann and Marthán Bester for hosting me during these fellowships.

\section{References}

Amano M, Yoshioka M. 2003. Sperm whale diving behavior monitored using a suction-cup attached TDR tag. Marine Ecology Progress Series 258: 291-295.

Andrews RD, Pitman RL, Ballance LT. 2008. Satellite tracking reveals distinct movement patterns for Type $B$ and Type $C$ killer whales in the southern Ross Sea, Antarctica. Polar Biology 31: 1461-1468.

Bester MN, de Bruyn PJN, Oosthuizen WC, Tosh CA, Mclntyre T, Reisinger RR, Postma M, van der Merwe DS, Wege M. 2011. The Marine Mammal Programme at the Prince Edward islands: 38 years of research. African Journal of Marine Science 33: 511-521.

Bestley S, Jonsen ID, Hindell MA, Guinet C, Charrassin J-B. 2013. Integrative modelling of animal movement: incorporating in situ habitat and behavioural information for a migratory marine predator. Proceedings of the Royal Society B 280: 20122262.

Block BA, Jonsen ID, Jorgensen SJ, Winship AJ, Shaffer SA, Bograd SJ, Hazen EL, Foley DG, Breed GA, Harrison A-L, Ganong JE, Swithenbank A, Castleton M, Dewar H, Mate BR, Shillinger GL, Schaefer KM, Benson SR, Weise MJ, Henry RW, Costa DP. 2011. Tracking apex marine predator movements in a dynamic ocean. Nature 475: 86-90.

Bodkin J, Ballachey B, Coletti H, Esslinger G, Kloecker K, Rice S, Reed J, Monson D. 2012. Long-term effects of the "Exxon Valdez" oil spill: sea otter foraging in the intertidal as a pathway 
of exposure to lingering oil. Marine Ecology Progress Series 447: 273-287.

Bonadonna F, Lea M-A, Dehorter O, Guinet C. 2001. Foraging ground fidelity and route-choice tactics of a marine predator: the Antarctic fur seal Arctocephalus gazella. Marine Ecology Progress Series 223: 287-297.

Bonfil R, Meÿer M, Scholl MC, Johnson R, O'Brien S, Oosthuizen H, Swanson S, Kotze D, Paterson M. 2005. Transoceanic migration, spatial dynamics, and population linkages of white sharks. Science 310: 100-103.

Boyd IL, Reid K, Bevan RM. 1995. Swimming speed and allocation of time during the dive cycle in Antarctic fur seals. Animal Behaviour 50: 769-784.

Committee on Taxonomy. 2013. List of marine mammal species and subspecies. Society for Marine Mammalogy, www. marinemammalscience.org [accessed 28 March 2013].

Cooke S. 2008. Biotelemetry and biologging in endangered species research and animal conservation: relevance to regional, national, and IUCN Red List threat assessments. Endangered Species Research 4: 165-185.

Costa DP, Robinson PW, Arnould JPY, Harrison A-L, Simmons SE, Hassrick JL, Hoskins AJ, Kirkman SP, Oosthuizen H, VillegasAmtmann S, Crocker DE. 2010. Accuracy of ARGOS locations of pinnipeds at-sea estimated using Fastloc GPS. PLOS ONE 5: e8677.

Dalton R. 2008. Acoustic sensors for rare porpoise. Nature 456: 431.

Davis RW, Jaquet N, Gendron D, Markaida U, Bazzino G, Gilly W. 2007. Diving behavior of sperm whales in relation to behavior of a major prey species, the jumbo squid, in the Gulf of California, Mexico. Marine Ecology Progress Series 333: 291-302.

Dean B, Freeman R, Kirk H, Leonard K, Phillips RA, Perrins CM, Guilford T. 2013. Behavioural mapping of a pelagic seabird: combining multiple sensors and a hidden Markov model reveals the distribution of at-sea behaviour. Journal of the Royal Society Interface 10: 20120570.

DeVries AL, Wohlschlag DE. 1964. Diving depths of the Weddell seal. Science 145: 292.

Diepenbroek M, Grobe H, Reinke M, Schindler U, Schlitzer R, Sieger R, Wefer G. 2002. PANGAEA-an information system for environmental sciences. Computers and Geosciences 28: $1201-1210$

Dragon A-C, Bar-Hen A, Monestiez P, Guinet C. 2012a. Comparative analysis of methods for inferring successful foraging areas from Argos and GPS tracking data. Marine Ecology Progress Series 452: 253-267.

Dragon A-C, Bar-Hen A, Monestiez P, Guinet C. 2012b. Horizontal and vertical movements as predictors of foraging success in a marine predator. Marine Ecology Progress Series 447: 243-257.

Dubois Y, Blouin-Demers G, Shipley B, Thomas D. 2009. Thermoregulation and habitat selection in wood turtles Glyptemys insculpta: chasing the sun slowly. Journal of Animal Ecology 78: 1023-1032.

Evans K, Lea M-A, Patterson TA. 2013. Recent advances in bio-logging science: technologies and methods for understanding animal behaviour and physiology and their environments. Deep-Sea Research // 88-89: 1-6.

Fedak MA. 2013. The impact of animal platforms on polar ocean observation. Deep-Sea Research // 88-89: 7-13.

Field IC, Bradshaw CJA, Burton HR, Sumner MD, Hindell MA. 2005. Resource partitioning through oceanic segregation of foraging juvenile southern elephant seals (Mirounga leonina). Oecologia 142: 127-135.

Field IC, Harcourt RG, Boehme L, de Bruyn PJN, Charrassin J-B, McMahon CR, Bester MN, Fedak MA, Hindell MA. 2012. Refining instrument attachment on phocid seals. Marine Mammal Science 28: E325-E332.
Freitas C, Lydersen C, Fedak M, Kovacs KM. 2008. A simple new algorithm to filter marine mammal Argos locations. Marine Mammal Science 24: 315-325.

Gales R, Alderman R, Thalmann S, Carlyon K. 2012. Satellite tracking of long-finned pilot whales (Globicephala melas) following stranding and release in Tasmania, Australia. Wildlife Research 39: 520-531.

Geschke K, Chilvers BL. 2009. Managing big boys: a case study on remote anaesthesia and satellite tracking of adult male New Zealand sea lions (Phocarctos hookeri). Wildlife Research 36: 666-674.

Godfrey JD, Bryant DM. 2003. Effects of radio transmitters: Review of recent radio-tracking studies. In: Williams M (ed.), Conservation applications of measuring energy expenditure of New Zealand birds: assessing habitat quality and costs of carrying radio transmitters. Science for Conservation 214: 83-95.

Hanson MB. 2001. An evaluation of the relationship between small cetacean tag design and attachment durations: a bioengineering approach. PhD thesis, University of Washington, USA.

Hanson MB, Baird RW. 1998. Dall's porpoise reactions to tagging attempts using a remotely-deployed suction-cup tag. Marine Technology Society Journal 32: 18-23.

Harkonen $T$, Jüssi $M$, Baimukanov $M$, Bignert $A$, Dmitrieva L, Kasimbekov Y, Verevkin M, Wilson S, Goodman SJ. 2008. Pup production and breeding distribution of the Caspian seal (Phoca caspica) in relation to human impacts. Ambio 37: 356-361.

Hart KM, Hyrenbach D. 2009. Satellite telemetry of marine megavertebrates: the coming of age of an experimental science. Endangered Species Research 10: 9-20.

Heaslip SG, Hooker SK. 2008. Effect of animal-borne camera and flash on the diving behaviour of the female Antarctic fur seal (Arctocephalus gazella). Deep-Sea Research I 55: 1179-1192.

Heide-Jørgensen MP, Kleivane L, Øien N, Laidre KL, Jensen MV. 2001. A new technique for deploying satellite transmitters on baleen whales: tracking a blue whale (Balaenoptera musculus) in the North Atlantic. Marine Mammal Science 17: 949-954.

Heide-Jørgensen MP, Stewart BS, Leatherwood S. 1992. Satellite tracking of ringed seals Phoca hispida off northwest Greenland. Ecography 15: 56-61.

Hetem RS, Strauss WM, Fick LG, Maloney SK, Meyer LCR, Shobrak M, Fuller A, Mitchell D. 2012. Activity re-assignment and microclimate selection of free-living Arabian oryx: responses that could minimise the effects of climate change on homeostasis? Zoology 115: 411-416.

Hindell MA, McMahon C. 2000. Long distance movement of a southern elephant seal (Mirounga leonina) from Macquarie Island to Peter 1 Øy. Marine Mammal Science 16: 504-507.

Hoelzel AR (ed.) 2009. Marine mammal biology: an evolutionary approach. Hoboken: John Wiley \& Sons, Ltd.

Hofmeyr GJG, Kirkman SP, Pistorius PA, Bester MN. 2012. Natal site fidelity by breeding female southern elephant seals in relation to their history of participation in the winter haulout. African Journal of Marine Science 34: 373-382.

Hooker SK, Baird RW. 2001. Diving and ranging behaviour of odontocetes: a methodological review and critique. Mammal Review 31: 81-105.

Hothorn T, Bretz F, Westfall P. 2008. Simultaneous inference in general parametric models. Biometrical Journal 50: 346-363.

James BS, Mclntyre T, Tosh CA, Bornemann H, Plötz J, Bester MN. 2012. Inter-population differences in diving behaviour of adult male southern elephant seals (Mirounga leonina). Polar Biology 35: 1759-1766.

Jaud T, Dragon A-C, Garcia JV, Guinet C. 2012. Relationship between chlorophyll a concentration, light attenuation and diving depth of the southern elephant seal Mirounga leonina. PLOS ONE 7: e47444.

Kooyman GL. 1965. Techniques used in measuring diving 
capabilities of Weddell seals. Polar Record 12: 391-394.

Kostoff RN. 2007. The difference between highly and poorly cited medical articles in the journal Lancet. Scientometrics 72 513-520.

Kuiken T, Kennedy S, Barrett T, Van de Bildt MWG, Borgsteede FH, Brew SD, Codd GA, Duck C, Deaville R, Eybatov T, Forsyth MA, Foster G, Jepson PD, Kydyrmanov A, Mitrofanov I, Ward CJ, Wilson S, Osterhaus ADME. 2006. The 2000 canine distemper epidemic in Caspian seals (Phoca caspica): pathology and analysis of contributory factors. Veterinary Pathology 43: 321-338.

Laidre KL, Heide-Jørgensen MP, Ermold W, Steele M. 2010. Narwhals document continued warming of southern Baffin Bay. Journal of Geophysical Research 115: C10049.

Laurance WF, Koster $H$, Grooten $M$, Anderson AB, Zuidema PA, Zwick S, Zagt RJ, Lynam AJ, Linkie M, Anten NPR. 2012. Making conservation research more relevant for conservation practitioners. Biological Conservation 153: 164-168.

Lea M-A, Hindell MA, Guinet C, Goldsworthy SD. 2002. Variability in the diving activity of Antarctic fur seals, Arctocephalus gazella, at lles Kerguelen. Polar Biology 25: 269-279.

Le Boeuf BJ, RM Laws (eds). 1994. Elephant seals: population ecology, behavior, and physiology. Berkeley: University of California Press.

Leung ES, Chilvers BL, Nakagawa S, Moore AB, Robertson BC. 2012. Sexual segregation in juvenile New Zealand sea lion foraging ranges: implications for intraspecific competition, population dynamics and conservation. PLOS ONE 7: e45389.

Lydersen C, Anders Nøst O, Lovell P, McConnell BJ, Gammelsrød T, Hunter C, Fedak MA, Kovacs KM. 2002. Salinity and temperature structure of a freezing Arctic fjord-monitored by white whales (Delphinapterus leucas). Geophysical Research Letters 29: 1-4.

Lydersen C, Freitas C, Wiig $\varnothing$, Bachmann L, Heide-Jorgensen M, Swift R, Kovacs K. 2012. Lost highway not forgotten: satellite tracking of a bowhead whale (Balaena mysticetus) from the critically endangered Spitsbergen stock. Arctic 65: 76-86.

Mate BR, Best PB, Lagerquist BA, Winsor MH. 2011. Coastal, offshore, and migratory movements of South African right whales revealed by satellite telemetry. Marine Mammal Science 27: 455-476.

Mate BR, Rossbach KA, Nieukirk SL, Wells RS, Irvine AB, Scott MD, Read AJ. 1995. Satellite-monitored movements and dive behavior of a bottlenose dolphin (Tursiops truncatus) in Tampa Bay, Florida. Marine Mammal Science 11: 452-463.

McConnell BJ, Chambers C, Fedak MA. 1992a. Foraging ecology of southern elephant seals in relation to the bathymetry and productivity of the Southern Ocean. Antarctic Science 4: 393-398.

McConnell BJ, Chambers C, Nicholas KS, Fedak MA. 1992b. Satellite tracking of grey seals (Halichoerus grypus). Journal of Zoology 226: 271-282.

McFarland R, Hetem RS, Fuller A, Mitchell D, Henzi SP, Barrett L. 2013. Assessing the reliability of biologger techniques to measure activity in a free-ranging primate. Animal Behaviour 85: 861-866.

McIntyre T, Ansorge IJ, Bornemann H, Plötz J, Tosh CA, Bester MN. 2011a. Elephant seal dive behaviour is influenced by ocean temperature: implications for climate change impacts on an ocean predator. Marine Ecology Progress Series 441: 257-272.

Mclntyre T, Bornemann H, Plötz J, Tosh CA, Bester MN. 2011b. Water column use and forage strategies of female southern elephant seals from Marion Island. Marine Biology 158: 2125-2139.

McIntyre T, de Bruyn PJN, Ansorge IJ, Bester MN, Bornemann H, Plötz J, Tosh CA. 2010a. A lifetime at depth: vertical distribution of southern elephant seals in the water column. Polar Biology 33: 1037-1048.
McIntyre T, Tosh CA, Plötz J, Bornemann H, Bester MN. 2010b. Segregation in a sexually dimorphic mammal: a mixed-effects modelling analysis of diving behaviour in southern elephant seals. Marine Ecology Progress Series 412: 293-304.

McMahon CR, Collier N, Northfield JK, Glen F. 2011. Taking the time to assess the effects of remote sensing and tracking devices on animals. Animal Welfare 20: 515-521.

McMahon CR, Field IC, Bradshaw CJA, White GC, Hindell MA. 2008. Tracking and data-logging devices attached to elephant seals do not affect individual mass gain or survival. Journal of Experimental Marine Biology and Ecology 360: 71-77.

Minimikawa S, Iwasaki T, Kishiro T. 2007. Diving behaviour of a Baird's beaked whale, Berardius bairdii, in the slope water region of the western North Pacific: first dive records using a data logger. Fisheries Oceanography 16: 573-577.

Mizroch SA, Tillman MF, Jurasz S, Straley JM, Von Ziegesar O, Herman LM, Pack AA, Baker S, Darling J, Glockner-Ferrari D, Ferrari M, Salden DR, Clapham PJ. 2011. Long-term survival of humpback whales radio-tagged in Alaska from 1976 through 1978. Marine Mammal Science 27: 217-229.

Morrel V. 2008. Can the vaquita be saved? Science 321: 767.

Naito Y. 2010. What is "bio-logging"? Aquatic Mammals 36: 307-322.

Naito Y, Bornemann H, Takahashi A, Mclntyre T, Plötz J. 2010. Fine-scale feeding behavior of Weddell seals revealed by a mandible accelerometer. Polar Science 4: 309-316.

Naito Y, Costa DP, Adachi T, Robinson PW, Fowler M, Takahashi A. 2013. Unravelling the mysteries of a mesopelagic diet: a large apex predator specializes on small prey. Functional Ecology 27: 710-717.

O'Malley Miller PJ, Shapiro AD, Deecke VB. 2010. The diving behaviour of mammal-eating killer whales (Orcinus orca): variations with ecological not physiological factors. Canadian Journal of Zoology 88: 1103-1112.

Osman LP. 2008. Population status, distribution and foraging ecology of Arctocephalus philippii (Peters 1866) at Juan Fernandez Archipelago. PhD thesis, Universidad Austral de Chile, Chile.

Padial AA, Nabout JC, Siqueira T, Bini LM, Diniz-Filho JAF. 2010. Weak evidence for determinants of citation frequency in ecological articles. Scientometrics 85: 1-12.

Pavlov VV, Wilson RP, Lucke K. 2007. A new approach to tag design in dolphin telemetry: computer simulations to minimise deleterious effects. Deep-Sea Research II 54: 404-414.

Phipps WL, Willis SG, Wolter K, Naidoo V. 2013. Foraging ranges of immature African white-backed vultures (Gyps africanus) and their use of protected areas in southern Africa. PLOS ONE 8: e52813.

R Core Team. 2012. R: a language and environment for statistical computing. Vienna: R Foundation for Statistical Computing.

Ramdohr S, Bornemann H, Plötz J, Bester MN. 2001. Immobilization of free-ranging adult male southern elephant seals with Immobilon ${ }^{\mathrm{TM}}$ (etorphine/acepromacine) and ketamine. South African Journal of Wildlife Research 31: 135-140.

Ropert-Coudert Y, Wilson RP. 2005. Trends and perspectives in animal-attached remote sensing. Frontiers in Ecology and the Environment 3: 437-444.

Sasaki-Yamamoto Y, Akamatsu T, Ura T, Sugimatsu H, Kojima J, Bahl R, Behera S, Kohshima S. 2013. Diel changes in the movement patterns of Ganges River dolphins monitored using stationed stereo acoustic data loggers. Marine Mammal Science 29: 589-605.

Sato K, Watanuki Y, Takahashi A, Miller PJ, Tanaka H, Kawabe R, Ponganis PJ, Handrich Y, Akamatsu, T, Watanabe $Y$, Mitani Y, Costa DP, Bost C-A, Aoki K, Amano M, Trathan P, Shapiro A, Naito Y. 2007. Stroke frequency, but not swimming speed, is related to body size in free-ranging seabirds, pinnipeds and 
cetaceans. Proceedings of the Royal Society B 274: 471-477.

Schipper J, Chanson JS, Chiozza F, Cox NA, Hoffmann M, Katariya V, Lamoreux J, Rodrigues ASL, Stuart SN, Temple HJ et al. 2008. The status of the world's land and marine mammals: diversity, threat and knowledge. Science 322: 225-230.

Schneider K, Baird RW, Dawson S, Visser I, Childerhouse S. 1998. Reactions of bottlenose dolphins to tagging attempts using a remotely-deployed suction-cup tag. Marine Mammal Science 14: 316-324.

Scholander PF. 1940. Experimental investigations on the respiratory function in diving mammals and birds. Hvalraadets Skrifter Norske Videnskaps-Akad 22: 1-131.

Schreer JF, Kovacs KM, O'Hara Hines RJ. 2001. Comparative diving patterns of pinnipeds and seabirds. Ecological Monographs 71: 137-162.

Shaffer SA, Costa DP. 2006. A database for the study of marine mammal behaviour: gap analysis, data standardization, and future directions. IEEE Journal of Oceanic Engineering 31: 82-86.

Sims DW, Southall EJ, Humphries NE, Hays GC, Bradshaw CJA, Pitchford JW, James A, Ahmed MZ, Brierley AS, Hindell MA, Morritt D, Musyl MK, Righton D, Shepard ELC, Wearmouth VJ, Wilson RP, Witt MJ, Metcalfe JD. 2008. Scaling laws of marine predator search behaviour. Nature 451: 1098-1102.

Sonne C, Teilmann J, Wright AJ, Dietz R, Leifsson PS. 2012. Tissue healing in two harbor porpoises (Phocoena phocoena) following long-term satellite transmitter attachment. Marine Mammal Science 28: E316-E324.

Staniland IJ, Boyd IL, Reid K. 2007. An energy-distance trade-off in a central-place forager, the Antarctic fur seal (Arctocephalus gazella). Marine Biology 152: 233-241.

Stewart J, Hazen E, Foley D, Bograd S, Gilly W. 2012. Marine predator migration during range expansion: Humboldt squid Dosidicus gigas in the northern California Current System. Marine Ecology Progress Series 471: 135-150.

Stewart BS, Leatherwood S, Yochem PK, Heide-Jørgensen MP. 1989. Harbor seal tracking and telemetry by satellite. Marine Mammal Science 5: 361-375.

Tyack PL, Zimmer WMX, Moretti D, Southall BL, Claridge DE,
Durban JW, Clark CW, D'Amico A, DiMarzio N, Jarvis S, McCarthy E, Morrissey R, Ward J, Boyd IL. 2011. Beaked whales respond to simulated and actual navy sonar. PLOS ONE 6: e17009.

Watanabe M, Tanabe S, Tatsukawa R, Amano M, Miyazaki N, Petrov EA, Khuraskin SL. 1999. Contamination levels and specific accumulation of persistent organochlorines in Caspian Seal (Phoca caspica) from the Caspian Sea, Russia. Archives of Environmental Contamination and Toxicology 37: 396-407.

Watanabe Y, Reyier E, Lowers R, Imhoff J, Papastamatiou Y. 2013. Behavior of American alligators monitored by multi-sensor data loggers. Aquatic Biology 18: 1-8.

Watanabe YY, Sato K, Watanuki Y, Takahashi A, Mitani Y, Amano M, Aoki K, Narazaki T, Iwata T, Minamikawa S, Miyazaki N. 2011. Scaling of swim speed in breath-hold divers. Journal of Animal Ecology 80: 57-68.

Watkins WA. 1981. Reaction of three species of whales Balaenoptera physalus, Megaptera novaeangliae, and Balaenoptera edeni to implanted radio tags. Deep-Sea Research A 28: 589-599.

Watkins WA, Tyack P. 1991. Reaction of sperm whales (Physeter catodon) to tagging with implanted sonar transponder and radio tags. Marine Mammal Science 7: 409-413.

Watts C, Empson R, Thornburrow D, Rohan M. 2012. Movements, behaviour and survival of adult Cook Strait giant weta (Deinacrida rugosa; Anostostomatidae: Orthoptera) immediately after translocation as revealed by radiotracking. Journal of Insect Conservation 16: 763-776.

Wilson R, McMahon C. 2006. Measuring devices on wild animals: what constitutes acceptable practice? Frontiers in Ecology and the Environment 4: 147-154.

Woodworth PA, Schorr GS, Baird RW, Webster DL, McSweeney DJ, Hanson MB, Andrews RD, Polovina JJ. 2012. Eddies as offshore foraging grounds for melon-headed whales (Peponocephala electra). Marine Mammal Science 28: 638-647.

Yasuda T, Katsumata H, Kawabe R, Nakatsuka N, Kurita Y. 2013. Identifying spawning events in the Japanese flounder Paralichthys olivaceus from depth time-series data. Journal of Sea Research 75: 33-40. 